TITLE:

\title{
Analysis of flow and heat transfer during the impingement of a diesel spray on a wall using large eddy simulation
}

\section{$\operatorname{AUTHOR}(S):$}

Kawanabe, Hiroshi; Komae, Jun; Ishiyama, Takuji

\section{CITATION:}

Kawanabe, Hiroshi ... [et al]. Analysis of flow and heat transfer during the impingement of a diesel spray on a wall using large eddy simulation. International Journal of Engine Research 2019, 20(7): 758-764

\section{ISSUE DATE:}

2019-09

URL:

http://hdl.handle.net/2433/264616

\section{RIGHT:}

This is the accepted manuscript of the following article: 'International Journal of Engine Research' Volume: 20 issue: 7 , page(s): 758-764. Copyright @ IMechE 2019. DOI: 10.1177/1468087418792381.; This is not the published version. Please cite only the published version. この論文は出版社版でありません。引用の際には出版社版をご確認ご利用ください。 


\title{
Analysis of Flow and Heat Transfer during the Impingement of a Diesel Spray on a Wall using Large Eddy Simulation
}

\author{
*Hiroshi Kawanabe, Jun Komae and Takuji Ishiyama \\ Graduate School of Energy Science, Kyoto University \\ Yoshida Honmachi, Sakyo-ku, Kyoto, 606-8501 Japan
}

Keywords: Diesel spray combustion, Large eddy simulation, Wall impingement, Heat transfer

\begin{abstract}
Numerical calculations were carried out to investigate the formation of a fuel-air mixture as well as ignition and combustion processes associated with a diesel spray impinging on a wall. This was performed by modeling the spray formed by injecting $\mathrm{n}$-heptane into a constant-volume vessel under high temperature and pressure, with the fuel droplets described by a discrete droplet model. The flow and turbulent diffusion processes were calculated based on the large eddy simulation method to simulate the formation of a local non-homogeneous mixture and the accompanying heat release. The flame structure and heat transfer to the wall during impingement were also assessed. The results show that heat transfer to the wall is increased in the peripheral region around the stagnation point, as a result of the high temperature and thin boundary layer. Conversely, in the outer region, the heat transfer decreases as the boundary layer becomes more developed.
\end{abstract}

\section{INTRODUCTION}

Both the exhaust emissions and thermal efficiency of modern diesel engines have been remarkably improved as a result of technological innovations, including high-pressure and multi-stage injection, exhaust gas recirculation, supercharging and exhaust after-treatment. However, there are continual demands for further improvements in emissions, fuel economy and engine output. As such, advanced technologies must be developed to precisely control the in-cylinder combustion processes, to allow the simplification and cost-reduction of engine systems. Additional increases in thermal efficiency will require reducing the heat loss to the chamber wall 
during combustion over short time spans. For this reason, the spray-wall interaction is important, as the behavior of the impinging spray has a significant effect on the formation of the fuel-air mixture, the combustion and the heat transfer. Previously, Kamimoto et al. investigated the heat transfer associated with the impingement of a diesel spray flame using a rapid compression apparatus [1], while Arcoumanis and Cutter studied the flow and heat transfer of an impinging diesel spray [2]. However, it is also important to investigate the fundamental mechanisms that control combustion and heat transfer. In addition to experimental approaches, computational fluid dynamics (CFD) is an effective means of analyzing combustion processes. Since spray development, ignition and combustion are very complicated phenomena, in which the fuel-air mixture is formed by an unsteady turbulent flow and chemical reactions progress simultaneously, Reynolds-averaged Navier-Stokes-based (RANS-based) CFD has frequently been used to simulate diesel combustion, due to its relatively low computational load. However, RANS is a time-averaged model, and so the calculated concentration distributions do not accurately reproduce the existence of locally rich and lean mixtures in a spray that have been observed in studies of instantaneous mixture distributions [3]. Therefore, calculations based on a large eddy simulation (LES) are thought to be more suitable for the purpose of analyzing the behavior of turbulent flows, the formation of non-homogeneous mixtures and the subsequent effects on ignition and combustion. Hori et al. simulated the development of a diesel spray using the KIVALES code [4], and the authors have investigated mixture formation, ignition and combustion processes employing LES [5]. In addition, Toda et al. studied a pulsating impinging jet by the LES method [6]. However, despite this prior work, the non-uniform combustion and heat release in fuel sprays and the effects of these parameters on the heat transfer process have not yet been sufficiently clarified.

In the present study, calculations were performed to examine sprays formed by single-stage injection impinging on a wall. On the basis of the results, the flame structure in the diesel spray, temporal changes in this structure and heat transfer to the wall are discussed.

\section{NUMERICAL SCHEME AND METHOD}

LES calculations were performed to simulate the mixture formation and ignition processes of a diesel spray in a constant-volume vessel under high pressure and temperature conditions. Two distances from the nozzle exit to the bottom wall $\left(x_{\mathrm{w}}\right)$ were modeled: $x_{\mathrm{w}}=74$ and $34 \mathrm{~mm}$. Figure 1 
shows the calculation grid for $x_{\mathrm{w}}=74 \mathrm{~mm}$, which consists of $160 \times 76 \times 98$ cells. The origin of the coordinate system is the nozzle exit, located $6 \mathrm{~mm}$ from the top wall, and the $x$-axis coincides with the spray axis.

The initial temperature in the vessel was $T_{\mathrm{i}}=1000 \mathrm{~K}$ and the pressure was $p_{\mathrm{i}}=4 \mathrm{MPa}$. The surrounding fluid was air with an oxygen mole fraction of $21 \%$. The wall temperature was fixed at $T_{\mathrm{w}}=500 \mathrm{~K}$ and the temperature distribution near the wall region was described by a quadratic curve, shown in Figure 2. Here, $\delta$ represents the distance from the wall and $\delta_{\mathrm{w}}$ is the characteristic length for the temperature distribution, with a fixed value of $10 \mathrm{~mm}$. The liquid fuel phase was described by the discrete droplet model (DDM). The initial fuel temperature was $338 \mathrm{~K}$ and the initial droplet velocity was set such that the spray tip penetration corresponded to that of an image obtained by the shadowgraph method. The initial direction of the fuel droplets was represented by the angle with respect to the $x$-axis, which was determined using normal random numbers with a standard deviation of $4.5^{\circ}$. The injection duration was set to $3.85 \mathrm{~ms}$ and approximately 25,000 parcels were injected in total during this period. The drag force on a droplet from the surrounding fluid was calculated by assuming the droplet to be a rigid sphere. Spray droplet break-up was calculated using the WAVE model [7] proposed by Liu et al., and the associated empirical constants $B_{0}$ and $B_{1}$ were determined to be 0.61 and 15 , respectively. These constants were adjusted based on an image obtained by the Mie-scattering method and experimental data regarding the fuel-air mixture distribution obtained by the planar laser-induced fluorescence (PLIF) method[3]. The change in the radius of a droplet due to evaporation and the temperature change resulting from heat transfer were calculated by diffusion equations under forced convection. The flow and turbulent diffusion processes were modeled by employing spatial Favre-filtered continuity, Navier-Stokes, species mass transport $\left(f_{m}\right)$ and enthalpy $(h)$ transport equations. In these calculations, the terms $\varrho, u_{j}, x_{j}, p$ and $t$ represent density, the $j$-component of velocity, the $j$-coordinate, pressure and time, respectively. The volume ratio of the gas in the cell, $V_{\mathrm{f}}$, was also introduced to account for the excluded droplet volume in the calculation cell.

The governing equations are written as:

$$
\frac{\partial \bar{\rho} V_{f}}{\partial t}+\frac{\partial \bar{\rho} \tilde{u}_{j}}{\partial x_{j}}=\overline{\dot{\rho}^{s}},
$$




$$
\begin{aligned}
& \frac{\partial \bar{\rho} \tilde{u}_{i} V_{f}}{\partial t}+\frac{\partial\left(\bar{\rho} \tilde{u}_{i} \tilde{u}_{j}+\tau_{i j}^{S G S}\right)}{\partial x_{j}}=-\frac{\partial \bar{p}}{\partial x_{i}}+\bar{F}_{i}^{s}, \\
& \frac{\partial \bar{\rho} \tilde{f}_{m} V_{f}}{\partial t}+\frac{\partial\left(\bar{\rho} \tilde{f}_{m} \tilde{u}_{j}+j_{i, m}^{S G S}\right)}{\partial x_{j}}=-\frac{\partial}{\partial x_{j}} \bar{j}_{j, m}+\bar{\omega}_{m}+{\overline{\dot{\rho}_{m}^{s}}}^{s}, \\
& \frac{\partial \bar{\rho} \tilde{h} V_{f}}{\partial t}+\frac{\partial\left(\bar{\rho} \tilde{h} \tilde{u}_{j}+q_{j}^{S G S}\right)}{\partial x_{j}}=-\frac{\partial p_{0} V_{f}}{\partial t}-\frac{\partial}{\partial x_{j}} \bar{q}_{j}+\bar{Q}^{s},
\end{aligned}
$$

where ${ }^{-}$denotes a spatially-filtered quantity, $\sim$ denotes a Favre-averaged value, $p_{0}$ is the mean pressure in the vessel, $\overline{\dot{\rho}^{s}}$ and $\overline{\dot{\rho}_{m}^{s}}$ are source terms related to the evaporation of fuel droplets, $\overline{F_{i}^{s}}$ and $\overline{\dot{Q}^{s}}$ are source terms for momentum and heat transfer from the fuel droplets, and $\bar{\omega}_{m}$ represents the rate at which species are produced by chemical reactions. The sub-grid scale (SGS) Reynolds stress, $\tau_{i j}{ }^{\mathrm{SGS}}$, in Equation (2) was obtained using the Smagorinsky model, and the constant $C_{\mathrm{s}}$ was fixed at 0.11. The Schmidt number, $S c$, and Prandtl number, $P r$, were both fixed at unity. The values of the SGS mass flux, $j_{i, m}{ }^{\mathrm{SGS}}$, in Equation (3) and the SGS heat flux, $q_{j}^{\mathrm{SGS}}$, in Equation (4) were obtained with the gradient diffusion model, and the turbulent Schmidt number and turbulent Prandtl number were set to 0.4 .

The implicit method was used during temporal integration and the SIMPLER method was employed for the purpose of pressure correction, using a staggered system. In the case of the momentum equation, a fourth-order Adams-Moulton scheme and a fourth-order central scheme were applied, while the convection terms in the mass and enthalpy equations were determined using a combination of the QUICK and first-order upstream schemes. A second-order central scheme was employed for other spatial differences. The calculation time step was $50 \mathrm{~ns}$ and the maximum Courant number was approximately 0.15 in the fine grid below the nozzle exit. A slip wall boundary condition was applied at all wall boundaries together with an adiabatic wall boundary condition at all locations except for the bottom wall opposite the nozzle. No gas ingress or egress was applied. Unevenly-spaced fine grids were applied around the non-slip wall, using a minimum grid size of $19 \mu \mathrm{m}$, which corresponds to an instantaneous $\mathrm{y}^{+}$of approximately 3 to 6 in the developed region. The statistical value of calculation results obtained with finer grids system was not appreciably different, and so this grid system was employed during the calculations. In addition, the effects of the SGS components on the fuel droplets were ignored. The injected fuel is assumed 
to be n-heptane and Schreiber's five-step reduced mechanism [8] was used to predict the progress of chemical reactions in the mixture, and certain frequency factors in this mechanism were modified to reproduce the ignition delay calculated based on full kinetics [9]. Chemical reactions were simulated based on averaged values in a calculation cell without using a turbulence interaction model.

Based on these models and procedures, calculations were carried out with a code written in-house. The mixture formation and combustion process in the case of a free spray were validated by comparison to experimental data. Details of the validation are described in previous work [2][3].

\section{RESULTS}

Based on these models and procedures, we simulated the process by which a fuel-air mixture is generated in conjunction with a diesel spray impinging on a vessel wall. Firstly, the spray flame behavior was calculated and compared with experimental data [10], using a nozzle orifice diameter , $d_{\mathrm{n}}$, of $0.123 \mathrm{~mm}$ and injection pressure values, $p_{\mathrm{inj}}$, of 50,100 or $150 \mathrm{MPa}$. The distance from the nozzle to the wall, $x_{\mathrm{w}}$, was $35 \mathrm{~mm}$ according to the experimental conditions. Figure 3 presents images showing the $\mathrm{OH}$ radical distributions and luminous flames obtained during experimental work along with the temperature, $T$, distributions along the $x-y$ plane based on LES calculations at $t$ $=0.6,1.2,1.8$ and $2.4 \mathrm{~ms}$. It is evident that the high temperature region resulting from the simulation corresponds to the $\mathrm{OH}$ radical distribution, and the flame development in the radial direction following impingement is similar to the calculation results.

The heat transfer process was subsequently investigated in detail. Here, the injection pressure and nozzle orifice diameter were set to $p_{\text {inj }}=120 \mathrm{MPa}$ and $d_{\mathrm{n}}=0.141 \mathrm{~mm}$, respectively. Figure 4 summarizes the temporal changes in the vessel pressure, $p_{\mathrm{f}}$, and the pressure rise rate, $\mathrm{d} p / \mathrm{d} t$, at $x_{\mathrm{w}}=$ 74 and $34 \mathrm{~mm}$, at vessel volumes of 300 and $150 \mathrm{~cm}^{3}$, respectively. These data show that the absolute values of $p_{\mathrm{f}}-p_{\mathrm{i}}$ and $\mathrm{d} p / \mathrm{d} t$ for $x_{\mathrm{w}}=34 \mathrm{~mm}$ were approximately twice those at $x_{\mathrm{w}}=74 \mathrm{~mm}$. Here, $\mathrm{d} p / \mathrm{d} t$ is correlated with the heat release rate, and this value is seen to increase rapidly following an ignition delay of approximately $0.5 \mathrm{~ms}$, after which it exhibits a sharp peak and then becomes constant for the duration of the injection. The heat release rate shapes are similar to a typical conventional diesel combustion process for both cases. In addition, the ignition delay for $x_{\mathrm{w}}$ 
$=34 \mathrm{~mm}$ is slightly longer than that at $74 \mathrm{~mm}$ as a result of cooling of the mixture by the relatively low-temperature wall.

The combustion and heat release processes for both cases are illustrated in Figure 5, which shows distributions of the fuel mixture fraction, $f$, and temperature, $T$, in the $x-y$ plane and the heat flux distribution, $q_{\text {wall }}$, on the bottom wall (the $y-z$ plane ) at $t=1,2,3$ and $4 \mathrm{~ms}$ from the injection start time. In Figure 5 (a) (at $x_{\mathrm{w}}=74 \mathrm{~mm}$ ), the spray develops and ignition occurs before impingement. Subsequently, the high-temperature combustion region approaches the wall. After impingement, the mixture spreads along the wall and rolls up. The simulated spray development and wall impingement processes were therefore all modeled realistically. The wall heat flux, $q_{\text {wall }}$, generally is increased in the impingement region but becomes relatively low near the stagnation point on the spray axis. The temperature near the spray axis is also relatively low compared with the outskirt region of the spray. However, the variation in $q_{\text {wall }}$ becomes larger near the spray axis. Therefore, further investigation of the $q_{\text {wall }}$ distribution near the spray axis will be required.

In Figure $5(\mathrm{~b})\left(x_{\mathrm{w}}=34 \mathrm{~mm}\right)$, the spray mixture impinges on the wall and develops along the wall before ignition occurs. The high-temperature combustion region spreads relatively widely compared with the $74 \mathrm{~mm}$ scenario and a larger roll-up vortex is formed near the wall and moves radially. In addition, $q_{\text {wall }}$ becomes larger in the central impingement region but is relatively small near the large roll-up vortex region.

To clarify the process by which heat transfer to the wall occurs, we explored the relationship between the instantaneous heat flux and the distributions of the parallel components of velocity and temperature. Figure 6 presents a schematic diagram showing the mixture distribution in the near-wall region, while Figure 7 shows the $\delta$ distributions of the $y$ components of velocity, $v$, and temperature, $T$, along with the $y$ distributions of the wall heat flux, $q_{\text {wall }}$, for both cases of (a) $x=$ $74 \mathrm{~mm}$ and (b) $x=34 \mathrm{~mm}$. In Figure $6, \mathrm{P}_{1}, \mathrm{P}_{2}, \mathrm{P}_{3}$ and $\mathrm{P}_{4}$ correspond to $y=0,5,10$ and $15 \mathrm{~mm}$, respectively. In addition to (b) $x=34 \mathrm{~mm}$, plots of the results obtained without reaction provide the distributions of temperature, $T_{\mathrm{nr}}$, velocity, $v_{\mathrm{nr}}$, and the "w/o reaction" $q_{\text {wall }}$ values to investigate the effect of combustion. Under all conditions, $q_{\text {wall }}$ increased in the central region compared with its magnitude away from the center. At the stagnation point, $v$ decreased, the temperature gradient increased and a velocity boundary layer gradually formed along the wall at the outskirt region where $q_{\text {wall }}$ decreased. This trend is especially evident at $34 \mathrm{~mm}$, such that $q_{\text {wall }}$ becomes extremely 
large in the region defined by $y<5 \mathrm{~mm}$. At the stagnation point, the spray flow was rapidly deflected from the spray-axis direction to the radial direction along the wall. Therefore, the temperature boundary layer became thinner and the wall heat flux increased. In this region, the instantaneous $\mathrm{y}^{+}$corresponding to the maximum value of $v$ was approximately 40 . In the outskirt region, the $\mathrm{y}^{+}$associated with the maximum $v$ decreased to 10 to 20 . The heat flux profiles generated without reaction exhibit a similar tendency, although the absolute values are reduced by approximately $75 \%$. As well, the velocity and temperature gradients calculated without reaction near the wall are lower than those obtained with combustion.

Figure 8 shows the instantaneous $x-y$ distributions of the velocity vector, $v$, and temperature, $T$, at the near-wall region for $x_{\mathrm{w}}=34 \mathrm{~mm}$ at $t=2 \mathrm{~ms}$. The high-speed spray stream meandered along the $\mathrm{x}$-axis toward the wall until reaching the near-wall region, at which point it bent significantly towards the radial direction. Near the wall downstream from $y=8 \mathrm{~mm}$, a velocity boundary layer gradually developed and the flow direction became parallel to the wall, where the heat flux decreased.

\section{CONCLUSIONS}

The sprays formed by single-stage injection with impingement on a wall were simulated, and the flame structure in the diesel spray, temporal changes in this structure and heat transfer to the wall were examined. The following conclusions were derived from the results.

(1) LES in conjunction with non-slip wall conditions and a fine grid near the wall provided a reasonable simulation of a diesel spray impinging on a wall.

(2) In the case of a shorter distance between the nozzle and wall, ignition occurred after impingement and a high-temperature region spread widely, along with the formation of a large roll-up vortex.

(3) The wall heat flux increased around the stagnation point. Away from the impingement region, the heat flux became relatively low.

(4) The flow of the main spray stream was drastically bent toward the radial direction at the near-wall region around the stagnation point, and the heat flux became larger around this area. In contrast, in the outskirt region, a velocity boundary layer gradually developed and the flow became parallel to the wall, where the heat flux decreased. 


\section{REFERENCES}

[1] Kamimoto, T., Takahashi, H., Kobayashi, H. and Matsuoka, S., Convestive Heat Transfer an Impinging Diesel Flame in a Rapid Compression Machine, SAE paper No. 821035, 1982.

[2] Arcoumanis, C. and Cutter, P. A., Flow and Heat Transfer Characteristics of Impinging Diesel Sprays Under Cross-Flow Conditions, SAE paper No. 950448, pp. 171-185, 1995.

[3] Kojima, H., Kawanabe, H. and Ishiyama, T., A Study on Mixture Formation Process in a Diesel Spray Using PLIF Method, Proceedings of THIESEL 2010, 2010, pp. 75-85.

[4] Hori, T., Senda, J., Kuge, T., and Fujimoto, H., Large Eddy Simulation of Non-Evaporative and Evaporative Diesel Spray in Constant Volume Vessel by Use of KIVALES, SAE paper No. 2006-01-3334, 2006.

[5] Kojima, H., Kawanabe, H. and Ishiyama, T., "LES Analysis of Mixture Formation and Combustion Processes in a Diesel Spray," SAE Int. J. Engines 5(2):2012, doi:10.4271/2011-01-1849.

[6] Toda, H. B., Cabrit, O., Truffin, K., Bruneaux, G. and Nicoud, F., Assessment of Subgrid-scale Models with a Large-eddy Simulation-dedicated Experimental Database: The Pulsatile Impinging Jet in Turbulent Cross-flow, Physics of Fluids 26, 075108 , 2014.

[7] Liu, A. B., Mather, D. and Reitz, R. D., Modeling the Effects of Drop Drag and Breakup on Fuel Sprays, SAE paper No. 930072, 1993.

[8] Schreiber, M., Sakak, A.S. and Lingens, A., "A Reduced Thermokinetic Model for the Autoignition of Fuels with Variable Octane Ratings", Proceedings of 25th international Symposium on Combustion:933-940, 1994.

[9] Miyoshi, A., KUCRS software library, revision 20110107m13, available from the author. See the web: http://akrmys.com/KUCRS/ for update information.

[10] Tatsumi, T. et. al., "A Study on the Wall Heat Loss in Diesel Spray Flame (First Report) -Effect of injection pressure on the heat flux-", Trans. of the Society of Automotive Engineers of Japan, 47(6) , pp. 1291-1296, 2016. 


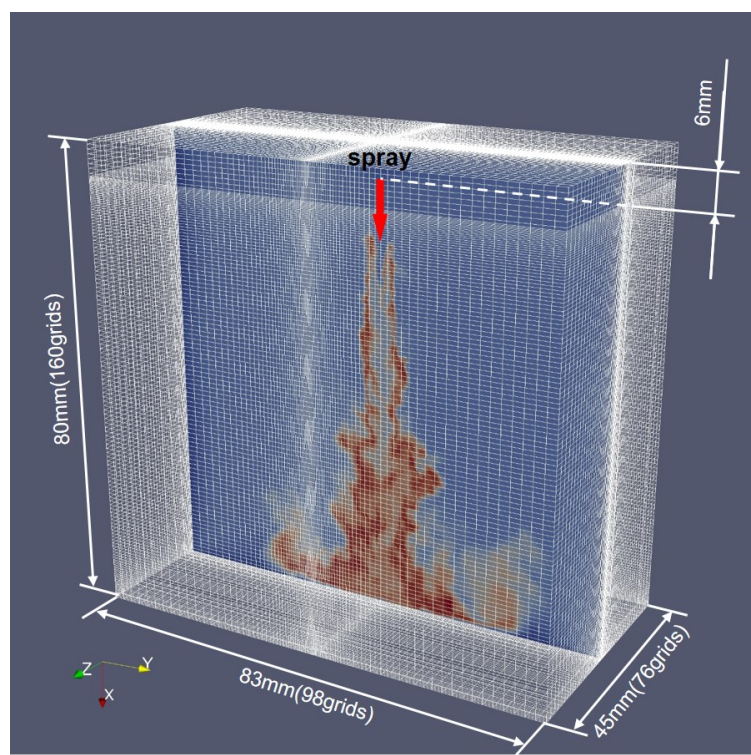

Figure 1 Schematic of grids system of calculation

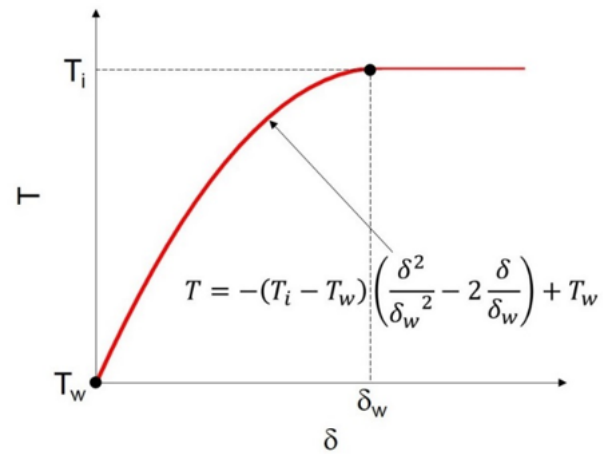

Figure 2 Boundary condition of temperature near wall region 


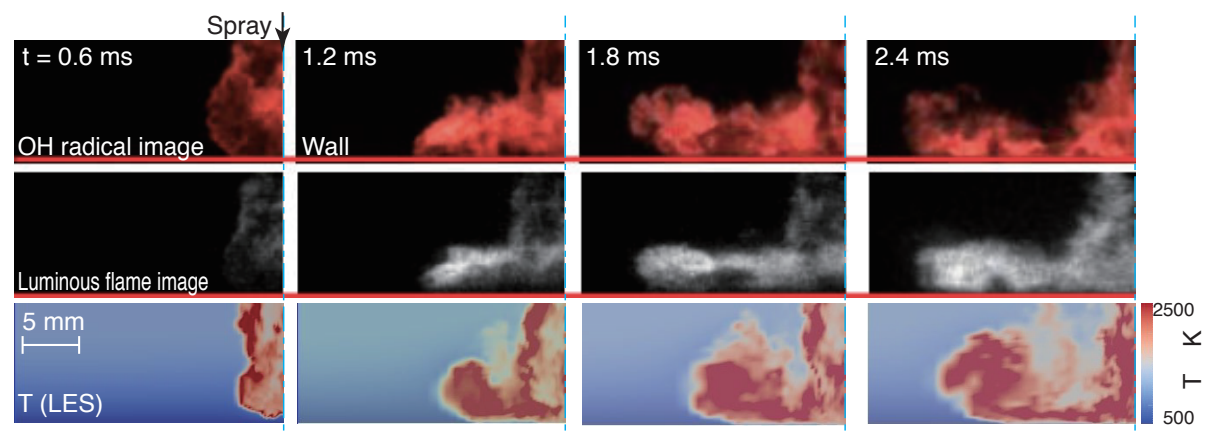

(a) $p_{\text {inj }}=50 \mathrm{MPa}$
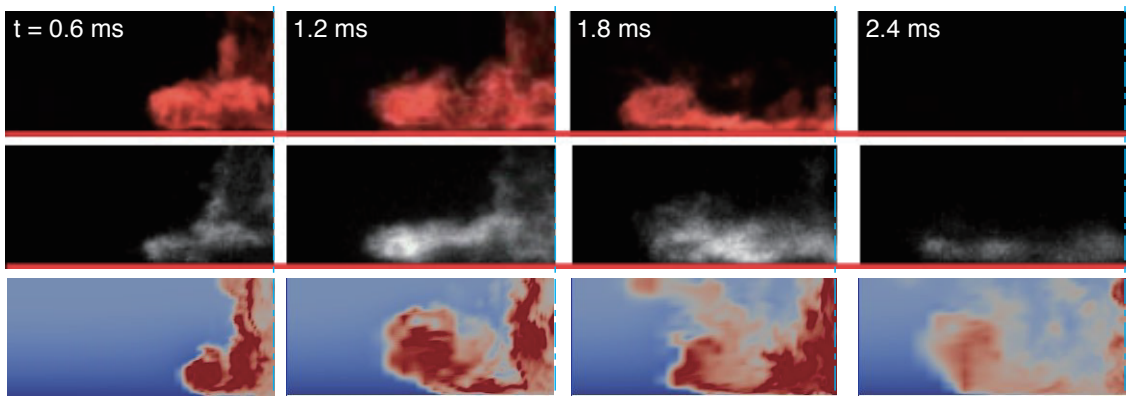

(b) $p_{\text {inj }}=100 \mathrm{MPa}$
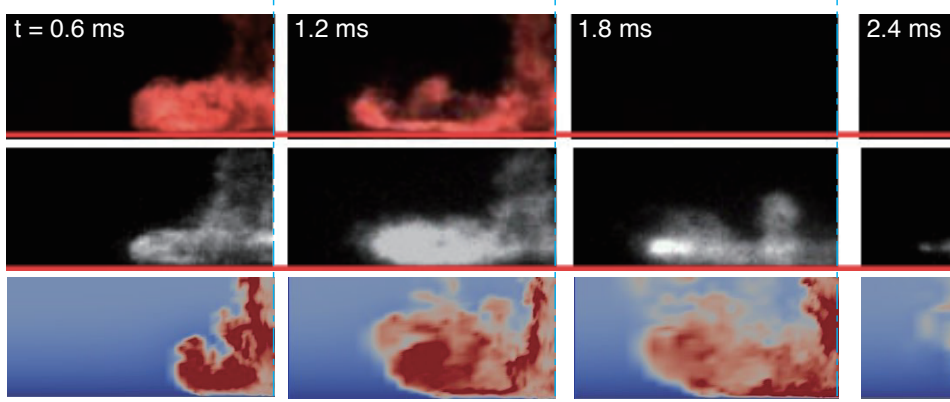

(c) $p_{\text {inj }}=150 \mathrm{MPa}$

Figure $3 \mathrm{OH}$ radical images and luminous flame images by the experiment[7] with temperature $T$ distributions on the $x-y$ plane by LES calcuation

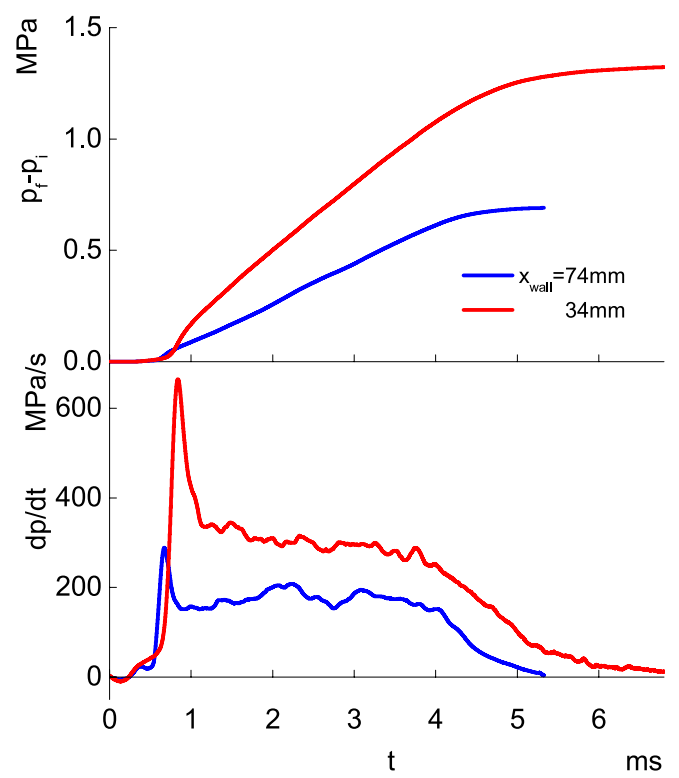

Figure 4 Temporal change of pressure $p_{\mathrm{f}}-p_{\mathrm{i}}$ and pressure rise rate $\mathrm{d} p / \mathrm{d} t$ 


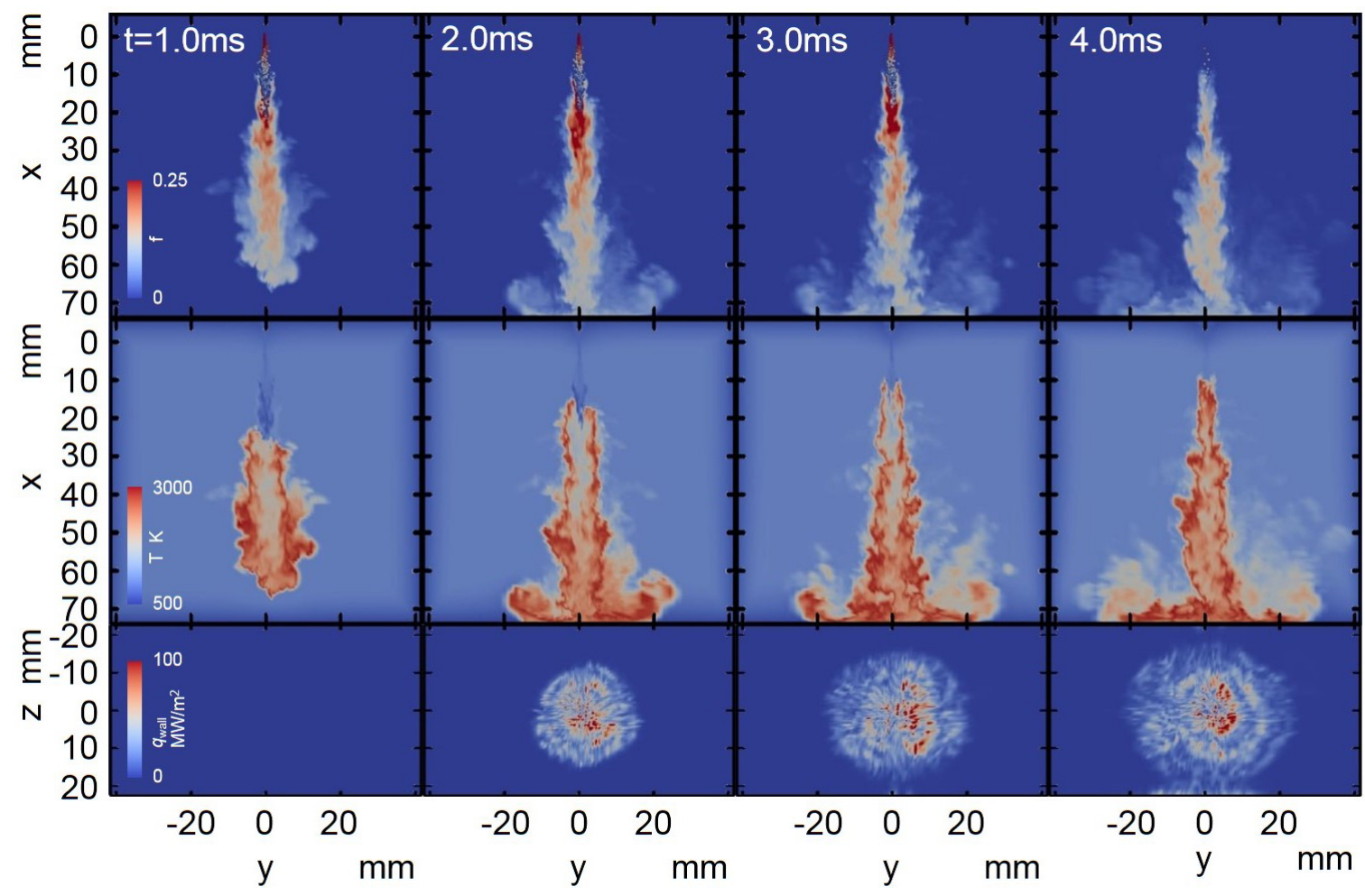

(a) $x_{\mathrm{w}}=74 \mathrm{~mm}$

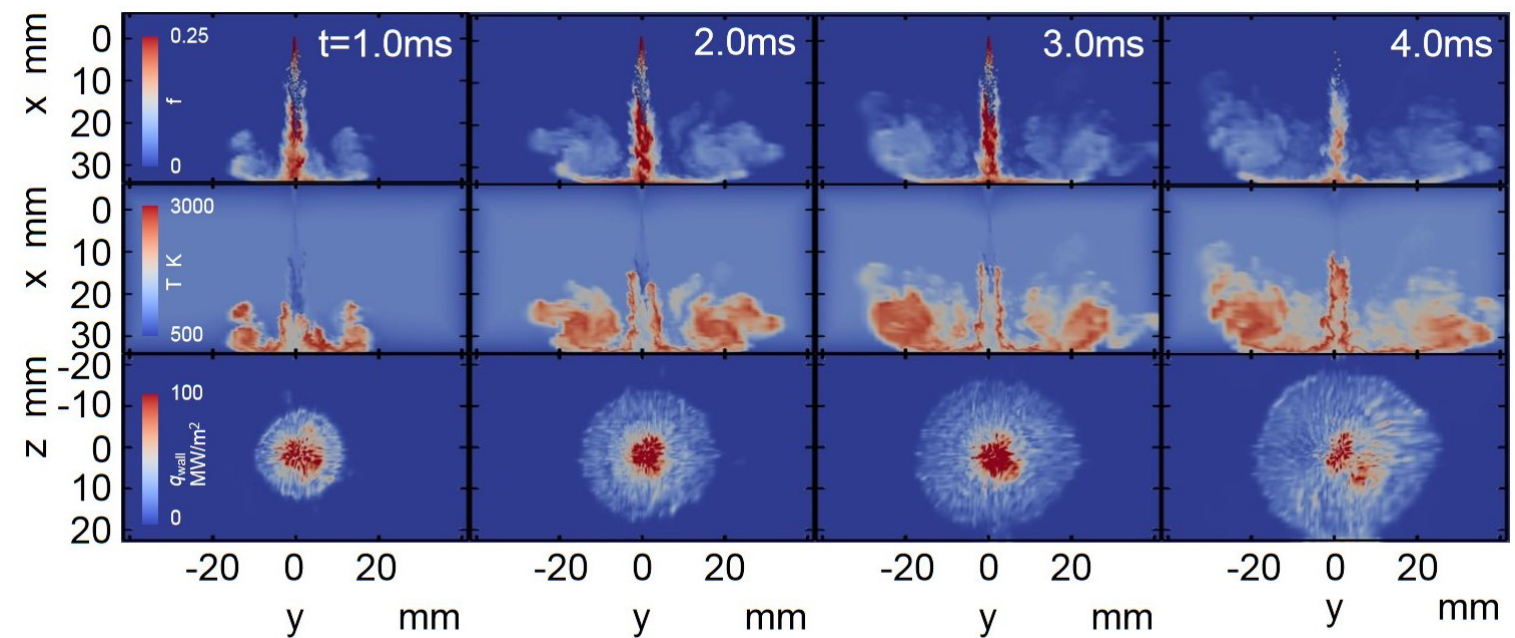

(b) $x_{\mathrm{w}}=34 \mathrm{~mm}$

Figure $5 x-y$ distributions of mixture fraction $f$ and temperature $T$ and $y-z$ distribution of heat-flux to wall $q_{\text {wall }}$ 


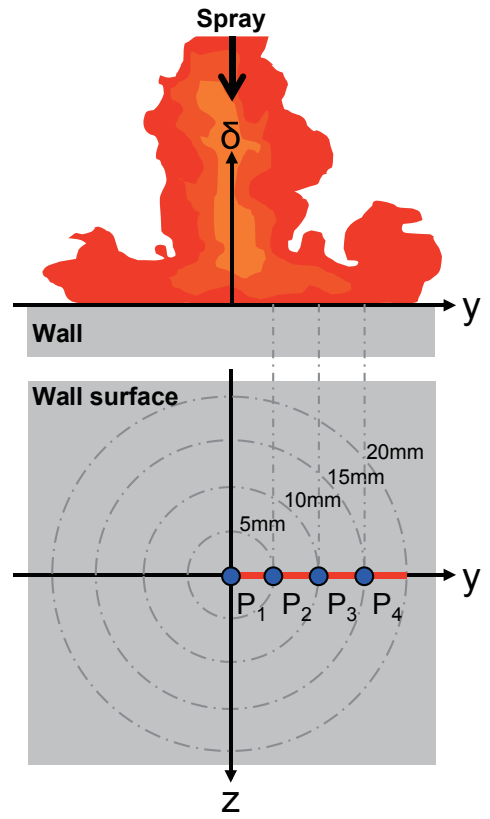

Figure 6 Schematic of mixture distribution of near wall region 

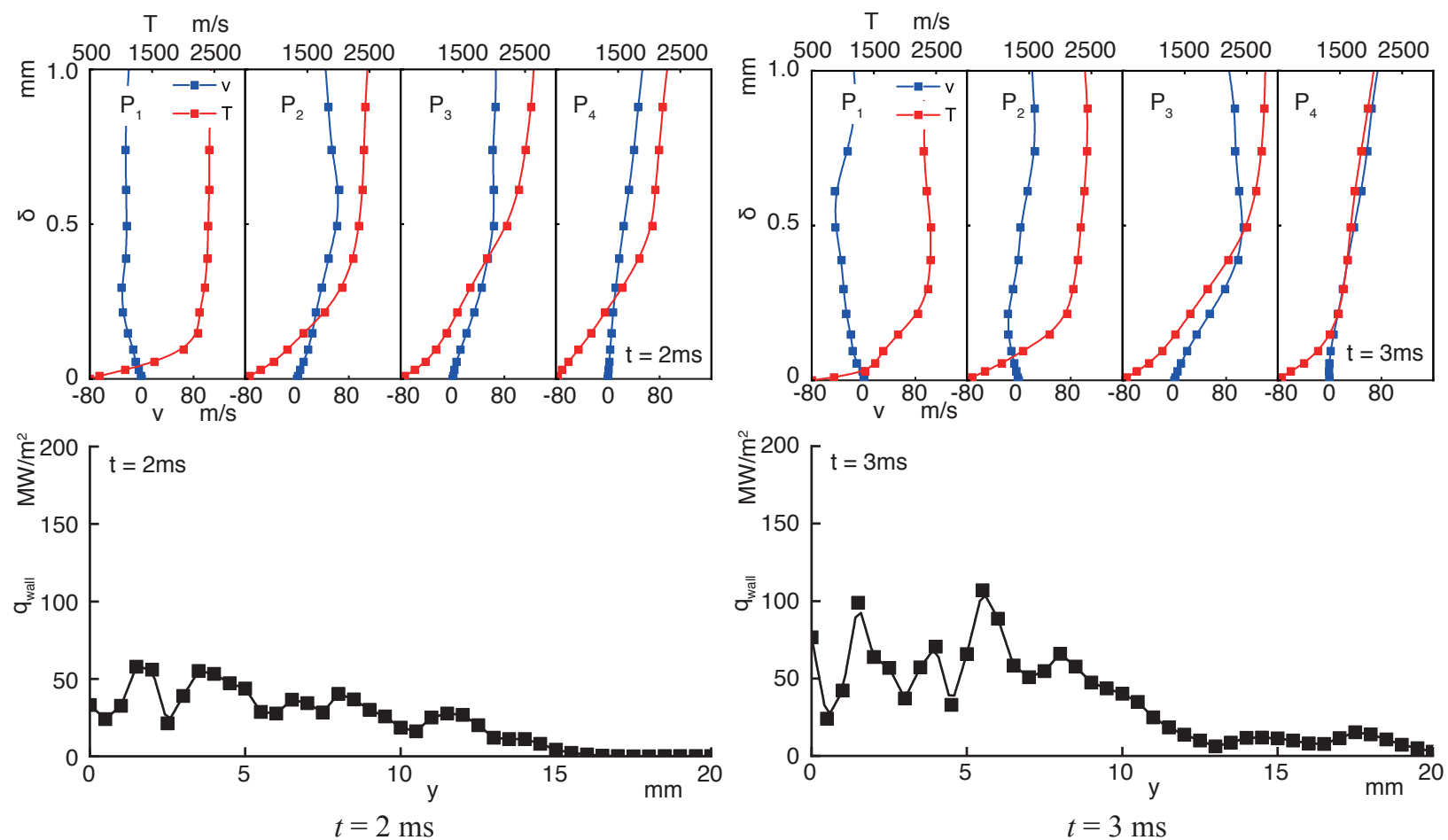

(a) $x_{\mathrm{w}}=74 \mathrm{~mm}$
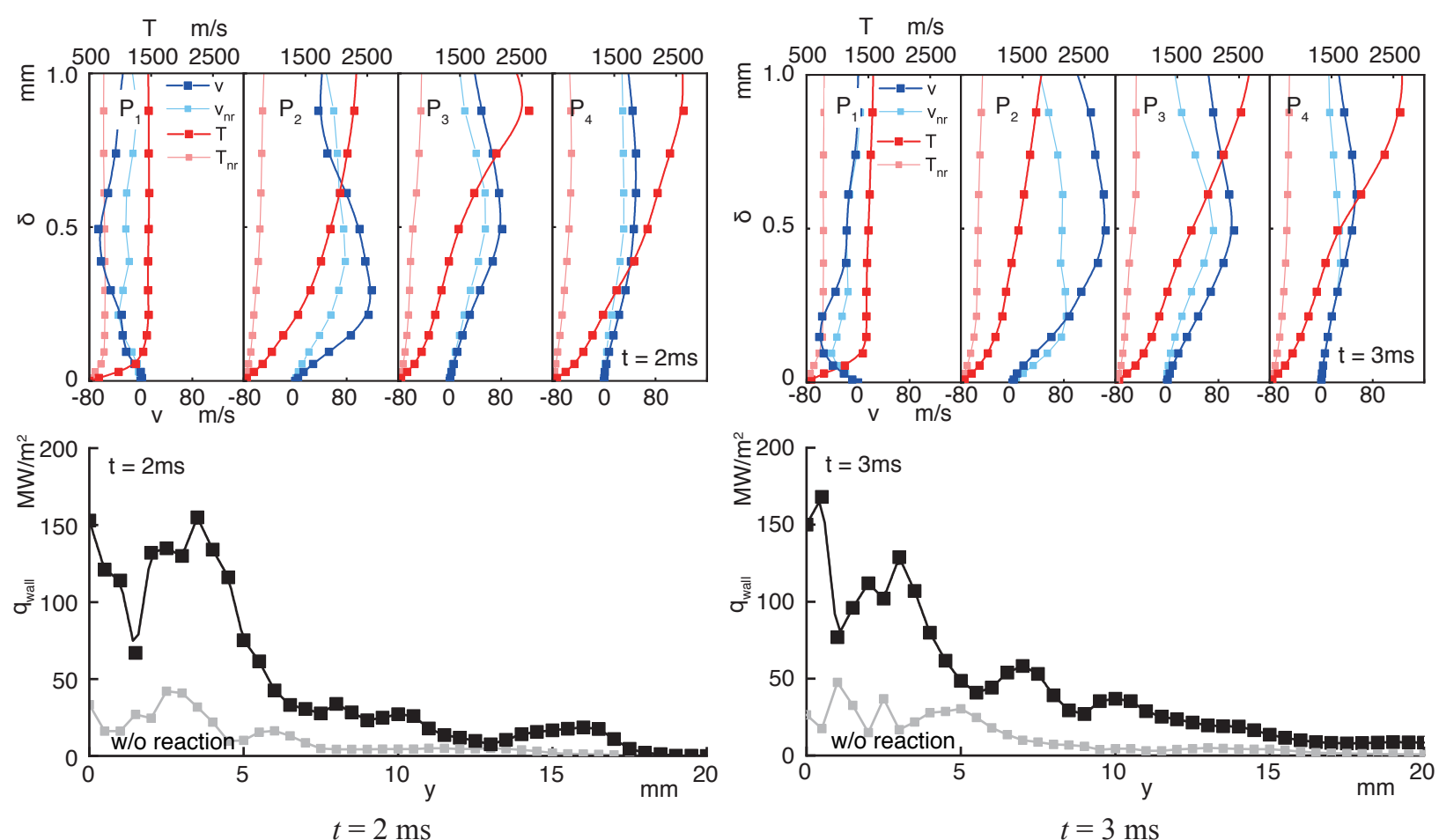

(b) $x_{\mathrm{w}}=34 \mathrm{~mm}$

Figure 7 Distributions of $y$-component of velocity $v$, temperature $T$ and heat flux $q_{\text {wall }}$ 


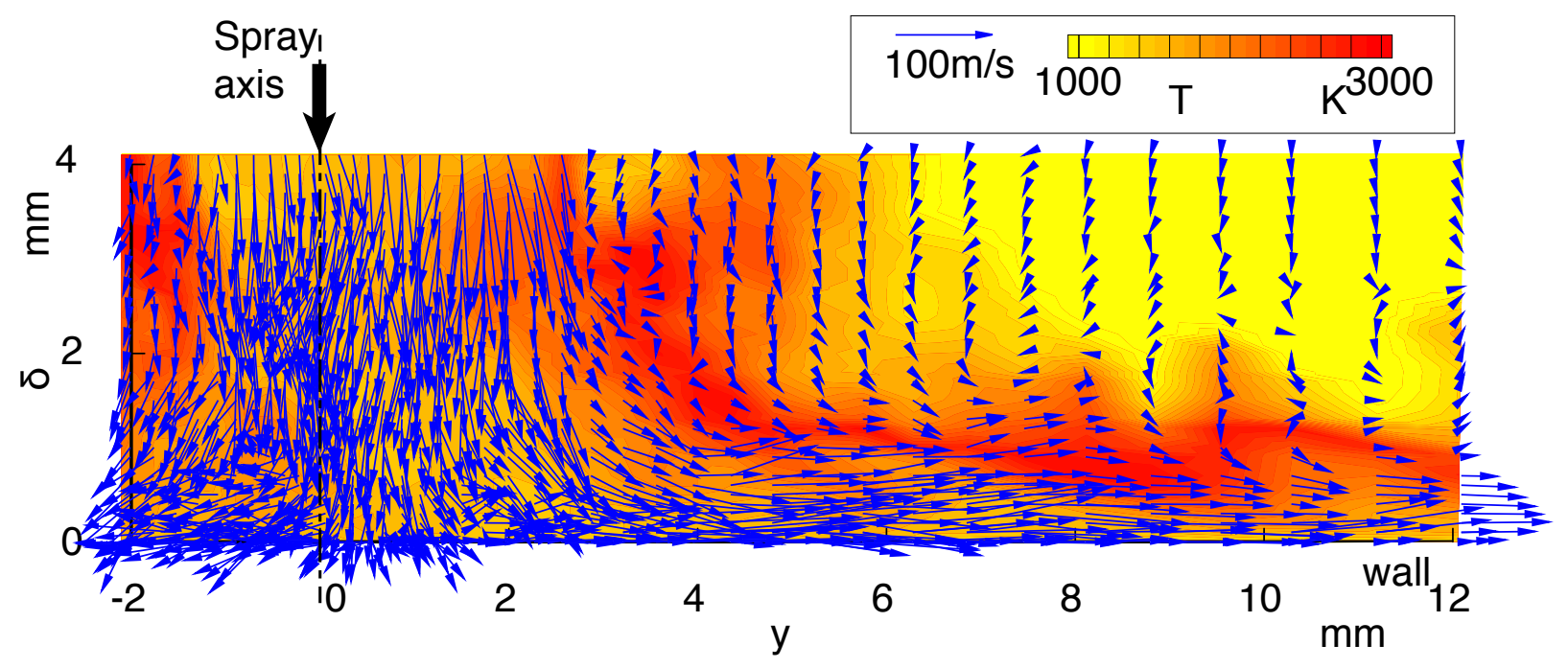

Figure 8 Distributions of velocity vector $\boldsymbol{v}$, temperature $T$ 